\title{
Research on the Combination of Corpus Resources and Micro Teaching Mode in Oral English Teaching for College English Majors
}

\author{
Baiping Huang \\ Pingxiang University, Pingxiang, Jiangxi, 337055, China
}

Keywords: Micro course; spoken English; corpus; teaching model

\begin{abstract}
As a new teaching form, the micro course brings great impact and challenge to the traditional classroom teaching. In this paper, based on the analysis of the concept and characteristics of the "mini course", the author puts forward the methods and achievements of the introduction of corpus in the design and development of oral English course, so as to improve the effectiveness and pertinence of the course. The study of spoken English corpus can reveal the characteristics and essence of oral English, which will bring profound influence on English teaching and accelerate the reform of oral English Teaching in china. This paper discusses the feasibility of the application of spoken English corpus research in the development of micro curriculum, and puts forward the design and development model of the micro course based on corpus.
\end{abstract}

\section{Introduction}

With the deepening of China's reform and opening up, international exchanges are increasing, our university graduates should not only have strong English reading ability and strong listening and translation skills and professional to obtain relevant information, but also have strong ability of speaking and writing, so that they can be directly involved in foreign exchange. The feedback information of the demand for talents indicates that the demand for college students' oral English ability will be higher and higher in the future. However, today's College Students' oral English ability is not optimistic [1-3]. A survey from the Zhejiang University professor Shao Yongzhen, the employer of college graduates in recent years, the comprehensive ability of English are generally lacking, especially on the output capacity of English verbal and written communication skills are even more so. Some employers believe that college graduates in the spoken language ability is only $5 \%$, poor or very poor for the $37 \%$ [4,5]. For the general university, the emphasis should be placed on strengthening the students' ability of listening and speaking and communicating. Therefore, in order to change the present situation, we must change the traditional teaching mode and idea, adjust teaching strategies, and explore the effective methods of oral English teaching.

The empirical research of psychology has proved that the concentration of human attention will be dispersed or transferred after 10-15 minutes, so the most effective teaching unit time is 10-15 minutes. Micro classroom dapper is known, teaching at the time of 10-15 minutes, there are clear teaching objectives and evaluation, will constitute a specific theme to the micro content solution concentration [6]. This course is increasingly becoming an important carrier of knowledge transfer based on the network platform. Since 2011, the exploration and practice of micro courses at home and abroad have been carried out in full swing. Although the network micro courses emerge in an endless stream, the forms are numerous and varied, but the summary and Research on the micro level of the top level design and the macro development concept [7]. There is a lack of research and Exploration on the integration of micro curriculum resources and classroom teaching resources, so some scholars worry about the phenomenon that the practice of micro course is backward. It is necessary and important to study the combination of corpus resources and micro teaching in oral English teaching for college English majors.

\section{Corpus resources overview}

A corpus is a collection of linguistic materials that are collected for certain purposes, sampled according to certain principles, and classified according to certain methods. After the corpus is input 
into the computer, after a certain degree of annotation or code, users can use the software to search and statistics the language items. English corpus, as a new teaching method, is gradually influencing the English classroom teaching.

The traditional oral English teaching method by students of mechanical memory, speak more and practice more, Practice makes perfect method. However, in the teaching practice, teachers do not have a systematic summary and summary of the contents of the students, so as to find out the general and common things $[8,9]$. It is better to use English learner corpus to obtain useful information about teaching and learning from the output of learners. Research on inter language corpora based on English teachers, teachers can make a systematic and accurate understanding of the students' problems in the process of learning, make teaching experience to support and validate the corpus data. Therefore, in order to improve the level of oral English teaching, we must first have a comprehensive, objective and scientific understanding of students' oral expression ability. This kind of understanding can not be achieved by the teaching experience alone, but the real situation reflected by the spoken English corpus is helpful to solve the problem.

A corpus based approach is the establishment and use of college students' oral English corpus resources by comparing English native speakers corpus of spoken English, oral English and comparative study of senior, intermediate and junior levels, found that the typical problems existing in the English oral expression, to determine the difficulty and focus in the teaching, the teacher's oral teaching thus greatly improving the teaching effect. Spoken corpus can also be used as a reliable, accurate and objective data source for the preparation of oral English teaching materials and the development of oral English teaching syllabus in the future.

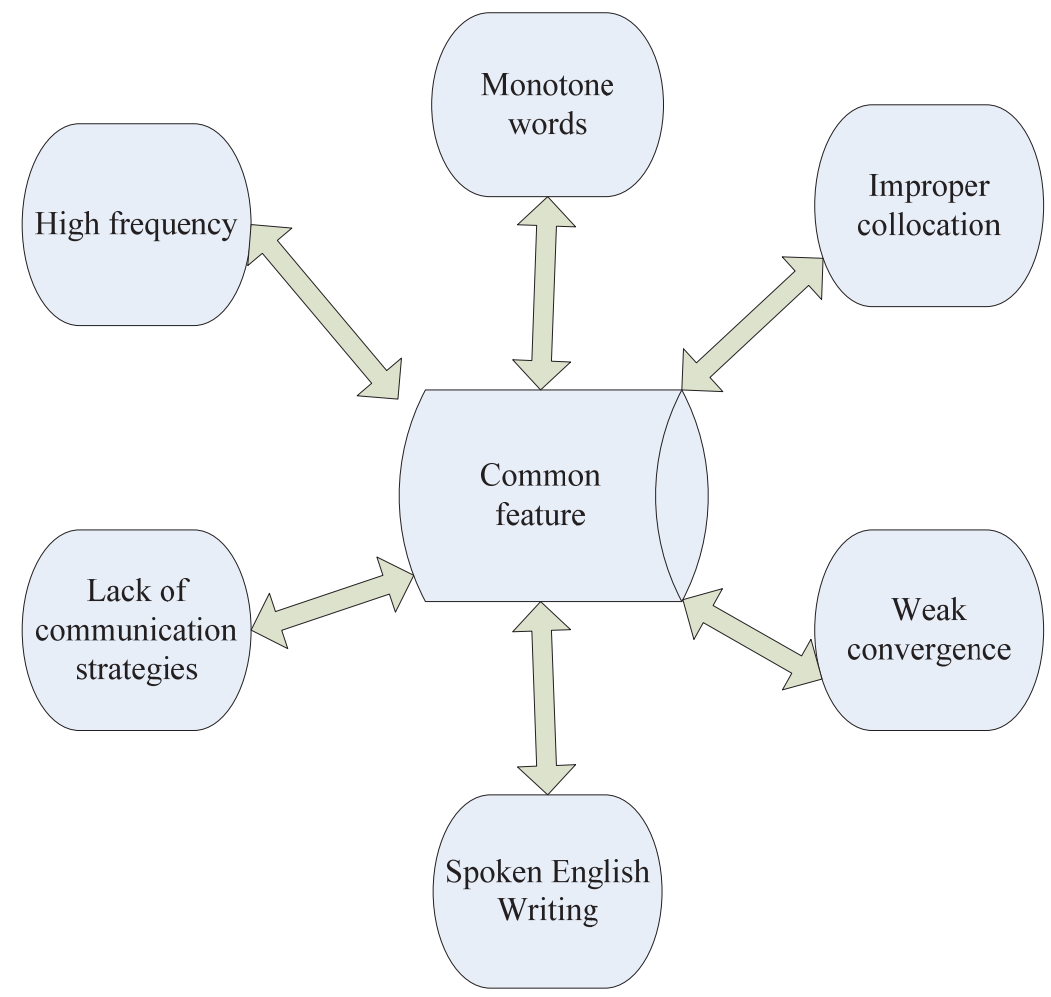

Fig. 1. Common feature map

By comparing the students' oral English output Chinese and native speakers of English, we can find the characteristics and problems of Chinese oral English learners. For example, some words, phrases or structures used too much or too little and incorrect expression. Some of these problems are common features of the group, as shown in Fig. 1, through the data statistics and analysis of the corpus can be determined. Therefore, we use the recent selection of teaching reform and practice of teaching reform and Practice on the ballot problem set up a small scale of College Students' oral English corpus, and make use of the data to make some preliminary. 


\section{Characteristics of Micro Teaching}

Many scholars and educators attach great importance to micro course and micro-class teaching with regard to their characteristics such as short duration, flexibility and smartness. Hu Tiesheng thinks of micro class teaching video as the main carrier, an organic combination of various teaching resources for teachers in the classroom teaching [10]. Liang Leming defines micro learning, micro courses, and micro class teaching as three key factors in defining creative teaching, Curriculum developers takes into account the systematic and integrity of the curriculum. Tang Junnian believes that micro video courses should be a complete and systematic curriculum system, which may consist of a number of thematic units and scattered micro video. In other words, the micro course is not equal to a micro video or a number of unrelated micro video courses consisting of a collection of resources, but a design science, the system of curriculum. As with the traditional curriculum, there should be a clear course objectives, syllabus, and complete the design of the content of each class [11, 12].The characteristics of the micro class as shown in Fig. 2.

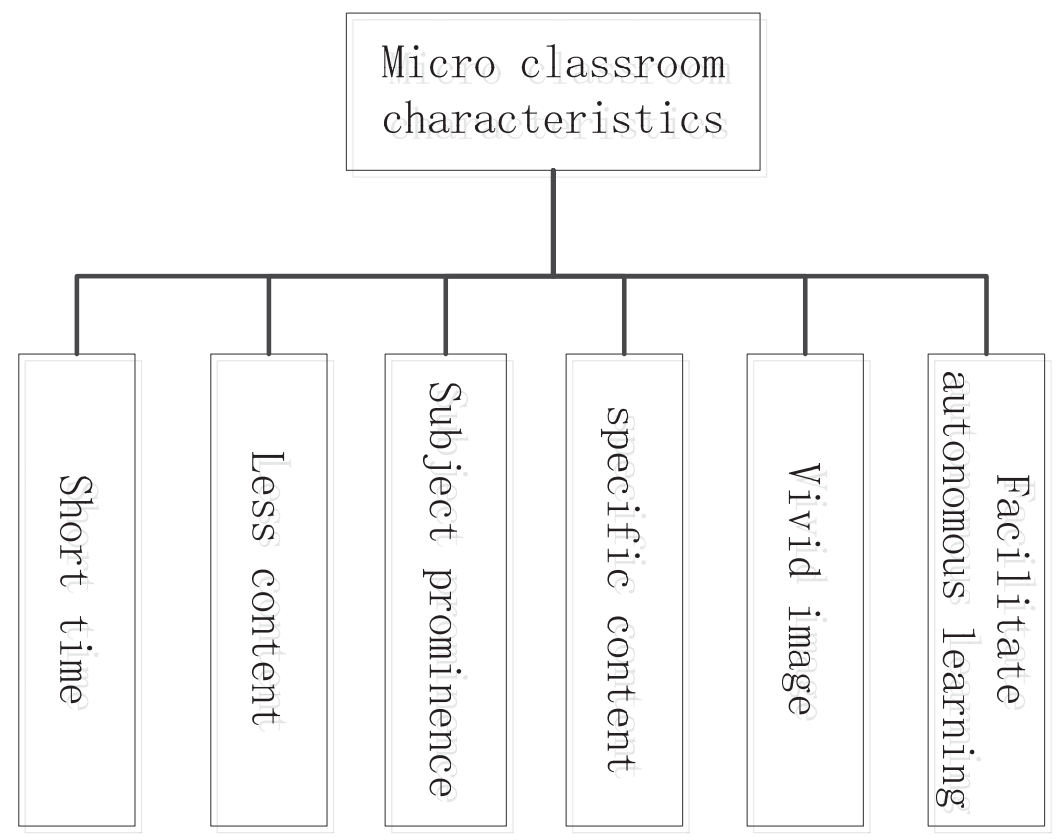

Fig. 2. Micro classroom characteristics

Micro lesson video is relatively short, generally about 10 to 20 minutes. A survey of College Teachers' micro class time is shown in Fig. 3. It has a small amount of resources, the teaching theme is small and fine, in a short period of time, the micro class in the teaching content, in addition to some unnecessary bedding and moisture, to solve the most needs of learners, most want to solve the problem. It is only around a point of knowledge or teaching links for further refinement of teaching, so the teaching objectives clear, focused, easy for learners to understand and master. Sometimes a short course is more useful than a dozen classes, so it has a great deal of knowledge and education. In the micro class, teachers can explain through audio, video, animation and other ways. Compared with single teaching and PPT, blackboard text presentation, multimedia based micro course video is more intuitive, attractive, easy for students to understand and grasp the knowledge points. 


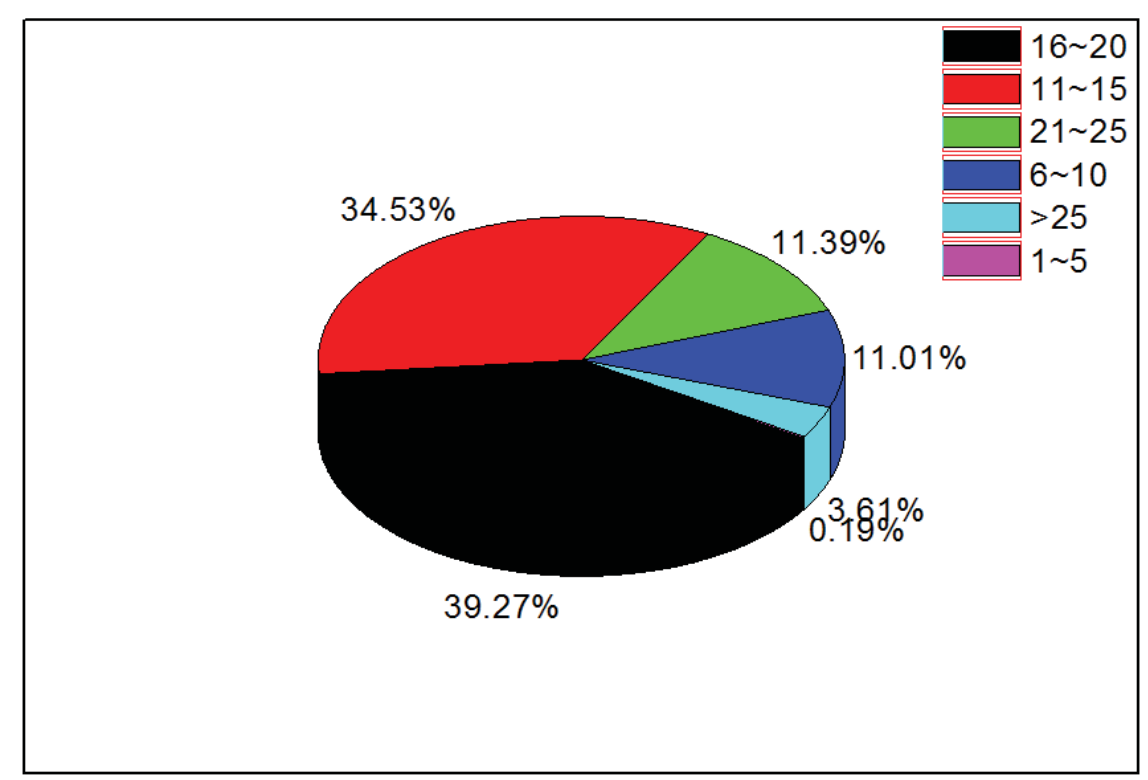

Fig. 3. A survey on the time of micro class(company: min)

Micro classroom is easy for learners to learn independently. Micro lesson video can be used not only in the classroom as a kind of teaching resources for students to learn, it means convenience and more time for students to study in their spare time. Students can arrange the learning time in a flexible way to make full use of their odds and ends. It is helpful to students' autonomous learning, and it is also helpful to cultivate students' good learning habits.

\section{The Design of Micro Course Model Based on Corpus}

The term "micro curriculum" does not refer to the micro content developed for micro teaching, but the practical teaching content, which is based on the construction approach. Although there are many differences between micro courses and traditional courses, the traditional curriculum design under the framework of the teaching method and other aspects of the experience is still available for micro course developer reference. As with the traditional curriculum, the curriculum design of vocational college English should reflect its value, and its design and development process should be based on the scientific theory and the development of the learner's inter language. To this end, we propose the following elements of the micro curriculum design model shown in Fig. 4.

First of all, the overall design of the course should be based on the analysis of the learner's learning needs, the analysis of the English requirements of the target position and the requirements of oral English teaching. In order to meet the needs and expectations of the learners, the micro curriculum should meet the requirements of learners. On the basis of this, the status of English micro courses in the whole professional system and the relationship with other courses was determined. 


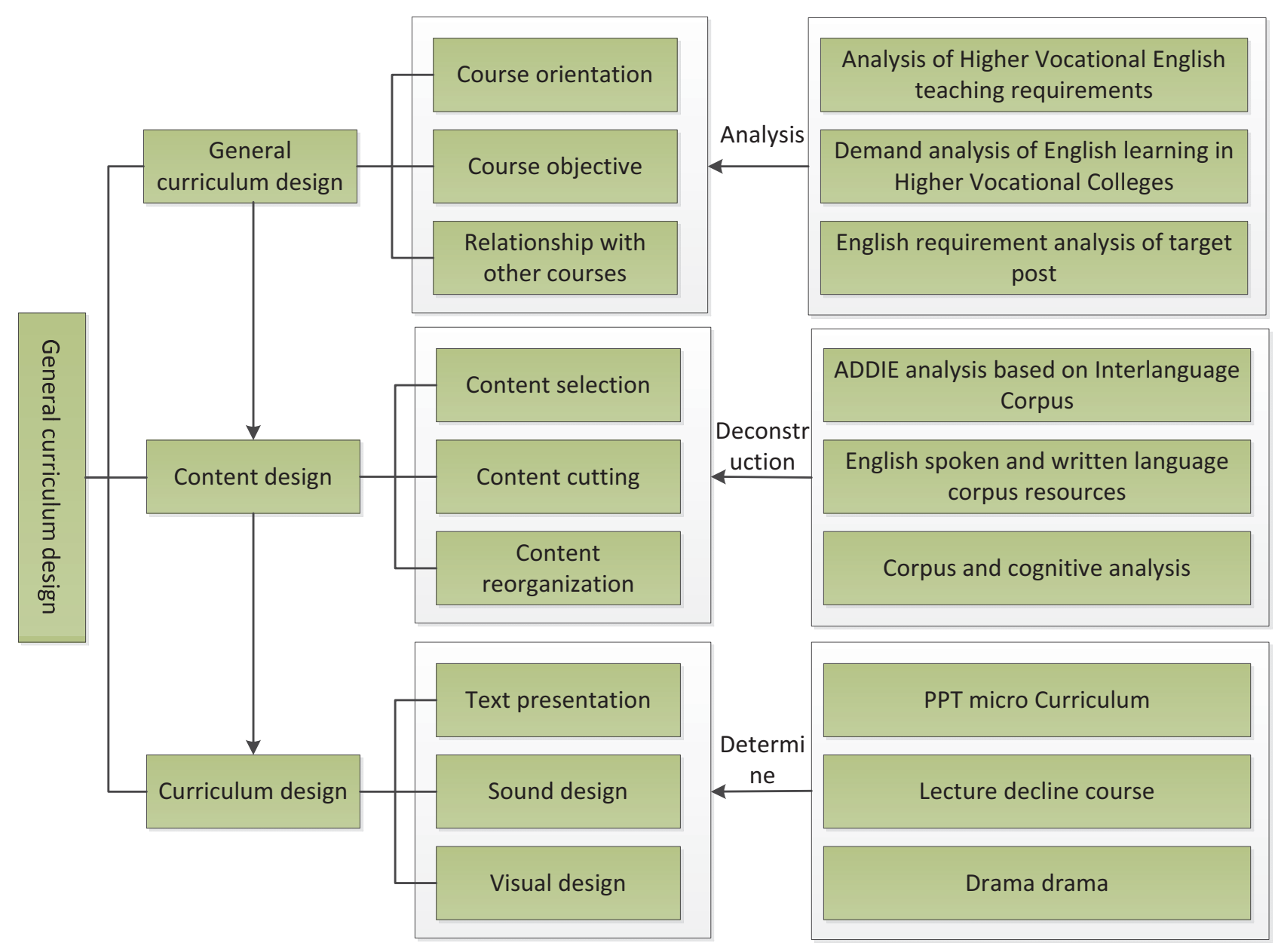

Fig. 4. Micro curriculum design model

Secondly, under the guidance of the overall design, the design of the content is based on the development of English learners' oral English. The selection and cutting of the content should be based on the relevant research results of corpus linguistics. However, the modeling and ordering of the learning content should not only take into account the development level of the students' English language, but also need to consider the cognitive rules of students' language learning.

Finally, the traditional form of the curriculum is relatively single, mainly based on teaching, objective knowledge of the subject, the lack of three-dimensional sense. According to the national unified curriculum standard design, the use of academic language to describe the scientific knowledge, their teaching mode and schedule be fixed, which can not cause the students' interest in learning. The micro course can be PPT by text, music, pictures, the design of PPT automatic playback function, and then converted into video. It can also be taken in accordance with the modular shooting, after the late clip conversion, the formation of micro courses.

\section{Summary}

In recent years, with the development of network and flipped classroom concept, short and pithy micro courses are more and more welcomed by learners of all ages. Based on the analysis of the concept and characteristics of the micro course, this paper puts forward the methods and achievements of introducing the corpus in the course design and development of oral English teaching in order to improve the effectiveness and pertinence of the micro course. This paper discusses the feasibility and application of the introduction of corpus research to the development of micro courses, and puts forward the model of the design and development of the corpus based micro course. 


\section{Acknowledgement}

This work is supported by Social Science Project of Jiangxi Province (13WX321).

\section{References}

[1] Zhao Y. The Application Study of Project Teaching in Higher Vocational Oral English Course [J]. Journal of Liaoning Higher Vocational, 2014.

[2] Chen X Z. Discussion on College Spoken English Teaching from the Perspective of Spoken Corpus [J]. Journal of Yangtze University, 2011.

[3] Yu J. Study on use of English phrasal verbs in oral English based on Spoken and Written English Corpus of Chinese Learners [J]. Foreign Language World, 2011:1-4.

[4] ZENG Xiao-Ling, Fujian Normal University. On the combination of oral English teaching and Online Autonomous Learning [J]. Journal of Hunan City University (Natural Science), 2016.

[5] Ke X H. Primary research on the combination of English for Computer Course teaching and IT outsourcing human resource pool[C]// Computer and Automation Engineering (ICCAE), 2010 The 2nd International Conference on. IEEE, 2010:472-475.

[6] Xia A T. Combination of vocational characteristics and improve the effect of oral English teaching vocational [J]. Journal of Nanchang College of Education, 2010.

[7] Sun W J. Studies on the construction of the corpus for the auto oral English for the Sino-German Know How majors under the cooperation between school and corporation [J]. Journal of Jiamusi Vocational Institute, 2016.

[8] Wang X. Main Problems in College Students' Oral English Learning and the Corresponding Teaching Strategies [J]. Higher Education of Social Science, 2013.

[9] Wang Q. The Exploration on Oral English Teaching Patterns and Strategies of College English in the View "Dialogue Teaching"[J]. Journal of Sichuan Vocational \& Technical College, 2013.

[10]Zhang H, Pei Y. On English Reading Teaching from the Perspective of Corpus Linguistics [J]. Science Education Article Collects, 2013.

[11] Madieva G, Orazbekova I, Tayeva R. LEXICAL APPROACH AS A COMBINATION OF APPLIED LINGUISTICS, CORPUS LINGUISTICS AND LANGUAGE TEACHING METHODOLOGY[M]// IRAL, International review of applied linguistics in language teaching :. J. Groos, 2015:287-317.

[12]Li-Yun X I, Gao Q, Zhao C Y. Corpus-based Approaches to College English Vocabulary Instruction [J]. Journal of Yunnan Agricultural University, 2013. 